\title{
Enthalpy of Sublimation in the Study of the Solid State of Organic Compounds. Application to Erythritol and Threitol
}

\author{
A. J. Lopes Jesus, Luciana I. N. Tomé, M. Ermelinda Eusébio,* and J. S. Redinha \\ Department of Chemistry, University of Coimbra, 3004-535, Coimbra, Portugal
}

Received: March 30, 2005; In Final Form: July 5, 2005

\begin{abstract}
The enthalpies of sublimation of erythritol and L-threitol have been determined at $298.15 \mathrm{~K}$ by calorimetry. The values obtained for the two diastereomers differ from one another by $17 \mathrm{~kJ} \mathrm{~mol}^{-1}$. An interpretation of these results is based on the decomposition of this thermodynamic property in a term coming from the intermolecular interactions of the molecules in the crystal $\left(\Delta_{\mathrm{int}} H^{\circ}\right)$ and another one related with the conformational change of the molecules on going from the crystal lattice to the most stable forms in the gas phase $\left(\Delta_{\text {conf }} H^{\circ}\right)$. This last term was calculated from the values of the enthalpy of the molecules in the gas state and of the enthalpy of the isolated molecules with the crystal conformation. Both quantities were obtained by density functional theory (DFT) calculations at the B3LYP/6-311G $++(\mathrm{d}, \mathrm{p})$ level of theory. The results obtained in this study show that the most important contribution to the differences observed in the enthalpy of sublimation are the differences in the enthalpy of conformational change $\left(13 \mathrm{~kJ} \mathrm{~mol}^{-1}\right)$ rather than different intermolecular forces exhibited in the solid phase. This is explained by the lower enthalpy of threitol in the gas phase relative to erythritol, which is attributed to the higher strength of the intramolecular hydrogen bonds in the former. The comparison of the calculated infrared spectra obtained for the two compounds in the gas phase supports this interpretation.
\end{abstract}

\section{Introduction}

The gas phase is commonly used as a reference state for thermodynamic properties on the grounds that at low pressure no account for the molecular interactions is needed. Hence, the tendency is to ascribe the differences of the molecular transfer process between a condensed state of matter and the gas state to molecular interactions in the former state. However, the structural differences in the gas state, even between similar compounds, are often big enough to affect the values determined experimentally for the transfer properties, sometimes exceeding those in the solid or liquid phase.

This paper deals with the enthalpy of sublimation of erythritol and threitol, diastereomers of 1,2,3,4-butanetetrol, and uses this property in the study of the solid state of these compounds. To follow the sublimation process, we have to define three quantities: enthalpy of sublimation, $\Delta_{\mathrm{sub}} H^{\circ}$, the variation of enthalpy associated with the transfer of the substance under consideration from the crystalline solid to gas phase; enthalpy of interaction, $\Delta_{\mathrm{int}} H^{\circ}$, the change in enthalpy associated to a hypothetical process corresponding to one mole of infinitely separated molecules with the conformation of the crystal joining together to form a mole of crystalline form, and enthalpy of conformational change, $\Delta_{\text {conf }} H^{\circ}$, defined as the enthalpy involved in the change of $1 \mathrm{~mol}$ of substance from the conformation in the crystal to the lowest Gibbs energy conformation in the gas state.

Sublimation can be considered a process taking place in two steps: First, the molecules pass from the solid state to a hypothetical state consisting of isolated molecules retaining their conformation; second, the molecular conformation changes from the one in the solid state to the one characteristic of the gas

* To whom correspondence should be addressed. state. Hence, the following relation holds for the enthalpy

$$
\Delta_{\text {int }} H^{\circ}=-\Delta_{\text {sub }} H^{\circ}+\Delta_{\text {conf }} H^{\circ}
$$

$\Delta_{\text {int }} H^{\circ}$ can be determined if $\Delta_{\text {conf }} H^{\circ}$ is calculated.

In this work, the enthalpy of sublimation is determined by calorimetry. For obtaining the enthalpy of conformational change, one needs to know the enthalpy of the isolated molecules in the gas state as well as the enthalpy of the isolated molecules which retain the geometry exhibited in the crystal. Both quantities are derived by theoretical calculations at the DFT level. By combining the data obtained experimentally for $\Delta_{\text {sub }} H^{\circ}$ with those obtained by theoretical calculations for the molecular conformation in the initial and final states, $\Delta_{\mathrm{int}} H^{\circ}$ is calculated from eq 1 . This property is straightforwardly related with molecular interactions in the solid and can be identified with $\Delta_{\text {sub }} H^{\circ}$ in cases for which $\Delta_{\text {conf }} H^{\circ}$ is negligible.

Another result from this research deserving to be pointed out is the contribution to the knowledge of the structure of compounds widely occurring in nature, that find numerous applications in food and pharmaceutical industries. ${ }^{1,2}$ Indeed, erythritol is used as a sweetener in the vast market of "light" and "reduced caloric" products. As it meets most of the criteria of an ideal excipient for pharmaceutical formulations, it has become a promising ingredient in the pharmaceutical industry. Moreover, the knowledge of the structures of erythritol and threitol is a valuable contribution to understanding the structures of this important class of higher molecular weight polyols.

\section{Materials and Experimental Methods}

The compounds under study were the best grade commercially available. The purity of erythritol, specified by the supplier Fluka, is higher than $99 \mathrm{~mol} \%$. The original substance was dried under vacuum at $353 \mathrm{~K}$ for 2 days before using. 
L-Threitol, purchased from Aldrich Chemical Company at 99 mole $\%$ purity, was dried under vacuum at $303 \mathrm{~K}$ for a few days. Both compounds are hygroscopic, in particular, threitol, and therefore, they were handled inside a glovebox under a dry nitrogen atmosphere.

Purity was checked by gas chromatography and elemental analysis. Chromatographic analysis was performed with an HP GC 6890/MSD5973 instrument under electron impact. The trimethylsilylated samples ${ }^{3,4}$ were analyzed using an HP-SMS (30 $\mathrm{m} \times 250 \mu \mathrm{m} \times 0.25 \mu \mathrm{m}$ ) column. The purities found for erythritol and L-threitol were $99.9 \%$ and $99.8 \%$, respectively.

Elemental analysis for carbon and hydrogen was carried out with an EA-1108 CHNS-O Fisons instrument. The results obtained for the mean and the standard deviation of three determinations, expressed as mass percent, were $\mathrm{C}=(39.43 \pm$ $0.05) \%$ and $\mathrm{H}=(8.35 \pm 0.15) \%$ for erythritol and $\mathrm{C}=(39.30$ $\pm 0.08) \%$ and $\mathrm{H}=(8.30 \pm 0.20) \%$ for $\mathrm{L}$-threitol. The values expected from the molecular formula are $\mathrm{C}=39.34 \%$ and $\mathrm{H}$ $=8.25 \%$. In addition to elemental analysis, the absence of water was also checked by IR spectroscopy using a Specac cell. The uptake of water from the atmosphere has a significant effect on the OH-stretching band of threitol at about $3200 \mathrm{~cm}^{-1}$.

We did not succeed in carrying out direct calorimetric measurements of the heat of sublimation. The values ascribed to this property were calculated from those obtained for the enthalpy of fusion and for the enthalpy of vaporization. The enthalpy of fusion determination was carried out with a PerkinElmer DSC7 calorimeter. Aluminum pans recommended for nonvolatile substances were used for the sample and for the reference. Nitrogen was used as the purging gas. Temperature calibration was performed with cyclohexane (Merck, GC, $x>$ 99.7\%) and indium (Perkin-Elmer, $x=99.99 \%$ ) and enthalpy calibration with indium. Naphthalene (CRM, LGC 2402) and biphenyl (CRM, LGC 2610, $x>99,9 \%$ ) were used to check both the temperature and the enthalpy calibrations. The values obtained for the onset temperature and enthalpy were the following: naphthalene $\left(T_{\text {fus }}=80.3 \pm 0.2{ }^{\circ} \mathrm{C}, \Delta_{\text {fus }} H=18.8 \pm\right.$ $\left.0.1 \mathrm{~kJ} \mathrm{~mol}^{-1}, n=4\right)$; biphenyl $\left(T_{\text {fus }}=68.9 \pm 0.1{ }^{\circ} \mathrm{C}, \Delta_{\text {fus }} H=\right.$ $\left.18.46 \pm 0.03 \mathrm{~kJ} \mathrm{~mol}^{-1}, n=5\right) . n$ stands for the number of experimental determinations. These values are in very good agreement with those reported in the literature. ${ }^{5}$ DSC curves traced at a heating rate of $2 \mathrm{~K} \mathrm{~min}^{-1}$ show no other phase transition but fusion for both erythritol and L-threitol.

The equipment used in the determination of the enthalpy of vaporization consisted of a C80 Setaram calorimeter connected to an Edwards high-vacuum system composed of a model 18 two-stage rotary pump and a model EXE500 turbomolecular pump. The vacuum attained was on the order of $10^{-4} \mathrm{~Pa}$. The cell used was a stainless-steel Knudsen effusion-type described elsewhere. ${ }^{6}$

The calorimeter constant was determined from the value found for the signal recorded for benzoic acid (CRM, LGC 2606, $x>99 \%) .{ }^{5}$ The calibration was checked by measuring the enthalpy of vaporization of hexadecane (Fluka, $x>99.8 \%$ ) at $398.15 \mathrm{~K}$. The value obtained was $\left(69.5 \pm 0.9 \mathrm{~kJ} \mathrm{~mol}^{-1}, n=\right.$ $7)$, which is in close agreement with that given in the literature $\left(69.4 \pm 0.7 \mathrm{~kJ} \mathrm{~mol}^{-1}\right) .5,7$

A weight between 4 and $11 \mathrm{mg}$ of the sample was completely vaporized after thermal equilibrium was reached. Vaporization of both compounds was carried out at $398.15 \mathrm{~K}$ and was accomplished in $2-5 \mathrm{~h}$. The corresponding effusion rates are $v$ $=5 \cdot 10^{-10}$ to $6 \cdot 10^{-10} \mathrm{~kg} \mathrm{~s}^{-1}$ for erythritol and $v=5 \cdot 10^{-10} \mathrm{~kg}$ $\mathrm{s}^{-1}$ for L-threitol. The saturation pressure estimated by Knudsen's equation was $2.6 \pm 0.4 \mathrm{~Pa}$ for erythritol and $1.5 \pm 0.2 \mathrm{~Pa}$
TABLE 1: Melting Points ( $\left.T_{\text {fus }}\right)$ and Enthalpies of Fusion $\left(\Delta_{\text {fus }} H^{\circ}\right)$ and Vaporization $\left(\Delta_{\mathrm{vap}} H^{\circ}\right)$ for Erythritol and L-Threitol $^{a}$

\begin{tabular}{clll}
\hline compound & \multicolumn{1}{c}{$T_{\text {fus }} / \mathrm{K}$} & $\begin{array}{c}\Delta_{\text {fus }} H^{\circ}\left(T_{\text {fus }}\right) / \\
\mathrm{kJ} \mathrm{mol}^{-1}\end{array}$ & $\begin{array}{c}\Delta_{\text {vap }} H^{\circ}(398.15 \mathrm{~K}) / \\
\mathrm{kJ} \mathrm{mol}^{-1}\end{array}$ \\
\hline erythritol & $391.2 \pm 0.4$ & $38.9 \pm 0.4$ & $97 \pm 1$ \\
& $(n=10)$ & $(n=10)$ & $(n=9)$ \\
L-threitol & $361.8 \pm 0.3$ & $29.1 \pm 0.2$ & $86 \pm 1$ \\
& $(n=7)$ & $(n=7)$ & $(n=8)$
\end{tabular}

${ }^{a}$ Uncertainties are taken to be the standard deviations. $n$ stands for the number of experimental determinations.

for L-threitol. The value obtained for erythritol is in good agreement with that given by other authors. ${ }^{8}$ Such a comparison cannot be made for threitol, since no data are available for this compound. Under the experimental conditions used, the values determined for $\Delta_{\mathrm{vap}} H$ match the standard enthalpy of vaporization.

To correct the results quoted for the enthalpy of fusion and for the enthalpy of vaporization to the temperature of 298.15 $\mathrm{K}$, we had to know the heat capacity in the corresponding temperature range. The values required for the heat capacity in the gas state were estimated from Joback's group increments. ${ }^{9}$ Those corresponding to liquid and solid states were determined by the enthalpic method ${ }^{10-12}$ using the Perkin-Elmer DSC7 power compensation calorimeter. Masses between 8 and $25 \mathrm{mg}$ were used in sealed Perkin-Elmer $40-\mu \mathrm{L}$ aluminum pans. The calorimeter was stabilized at an initial temperature for at least $5 \mathrm{~min}$. Then, the temperature was raised by $3 \mathrm{~K}$ at a scanning rate $\beta=2 \mathrm{~K} \cdot \mathrm{min}^{-1}$, and as the final temperature was reached, a 5-min stabilization period was kept. Baseline runs with empty pans, correction factor determination, verification standard, and sample runs were operations undertaken for each $C_{\mathrm{p}}$ determination. These operations, several runs for each, were always performed on the same day. The calculated $C_{\mathrm{p}}$ values are assigned to the temperature corresponding to the mean of the scanned temperature range. For each temperature, three or four independent samples were used. Heat capacity calibration was made using synthetic sapphire (RM, NIST 720) ${ }^{5,13}$ and confirmation using benzoic acid (SRM, LGC 2606) ${ }^{5,14}$ and urea (SRM, NIST 2152). ${ }^{15}$ Accuracy greater than $1.5 \%$ was achieved in the entire temperature range studied.

\section{Results}

3.1. Thermodynamic Data. The results obtained for the enthalpy of fusion and the enthalpy of vaporization of erythritol and threitol are presented in Table 1. From standard thermodynamics, the following expression is deduced to calculate the value of the standard enthalpy of sublimation at $298.15 \mathrm{~K}$

$$
\begin{aligned}
& \Delta_{\text {sub }} H^{\circ}(298.15 \mathrm{~K})=\int_{298.15}^{T_{\text {fus }}} C_{\mathrm{p}}^{\mathrm{s}} \mathrm{d} T+\Delta_{\text {fus }} H^{\circ}\left(T_{\text {fus }}\right)+ \\
& \int_{T_{\text {fus }}}^{398.15} C_{\mathrm{p}}^{\mathrm{l}} \mathrm{d} T+\Delta_{\text {vap }} H^{\circ}(398.15 \mathrm{~K})+\int_{398.15}^{298.15} C_{\mathrm{p}}^{\mathrm{g}} \mathrm{d} T
\end{aligned}
$$

The heat capacity values of both isomers in solid $\left(C_{\mathrm{p}}^{\mathrm{s}}\right)$, liquid $\left(C_{\mathrm{p}}^{\mathrm{l}}\right)$, and gas $\left(C_{\mathrm{p}}^{\mathrm{g}}\right)$ phases at different temperatures are given in Table 2 . The values for the standard enthalpy of sublimation at $298.15 \mathrm{~K}$ were calculated by eq 2 using the data given in Tables 1 and 2 and are included in Table 3.

Two results for $\Delta_{\text {sub }} H^{\circ}$ of erythritol at $298.15 \mathrm{~K}$ are given in the literature: ${ }^{8,16} 135$ and $157 \mathrm{~kJ} \mathrm{~mol}^{-1}$. The value obtained in the present work is close to the first and significantly different from the second one. For threitol, no other results are available in the literature. 
TABLE 2: Heat Capacity of Erythritol and L-Threitol in Solid, Liquid, and Gas States and the Values Calculated for the Integrated Heat Capacity Terms of Eq $2^{a}$

\begin{tabular}{ccr}
\hline compound & \multicolumn{1}{c}{$\begin{array}{c}\text { relationships established between } C_{\mathrm{p}} \text { and } T \\
\left.\text { (results in J mol } \mathrm{K}^{-1}\right)\end{array}$} & $\begin{array}{c}\text { integrated heat capacity term/ } \\
\mathrm{kJ} \mathrm{mol}^{-1}\end{array}$ \\
\hline erythritol & $C_{\mathrm{p}}^{\mathrm{s}}=-26.073+0.6399 T(n=4)(298.15 \mathrm{~K}$ to $348.15 \mathrm{~K})$ & 18.04 \\
& $C_{\mathrm{p}}^{\mathrm{l}}=335 \pm 1^{b}(T=398.15 \mathrm{~K})$ & -16.72 \\
& $C_{\mathrm{p}}^{\mathrm{g}}=17.052+0.532 T-3.218 \times 10^{-4} T^{2}+7.46 \times 10^{-8} T^{3 c}$ & 12.31 \\
L-threitol & $C_{\mathrm{p}}^{\mathrm{s}}=-136.0+0.9985 T(n=3)(298.15 \mathrm{~K}$ to $338.15 \mathrm{~K})$ & 11.90 \\
& $C_{\mathrm{p}}^{\mathrm{l}}=201.3+0.3310 T(n=3)(323.15 \mathrm{~K}$ to $398.15 \mathrm{~K})$ & -16.72
\end{tabular}

${ }^{a} n$ stands for the number of temperature values at which determinations were made within the given range. ${ }^{b}$ Mean of three values determined at $T=398.15 \mathrm{~K} .{ }^{c}$ Based on the expression proposed in ref 9 .

TABLE 3: Enthalpies of Sublimation $\left(\Delta_{\mathrm{sub}} H^{\circ}\right)$, Conformational Change $\left(\Delta_{\text {conf }} H^{\circ}\right)$, and Interaction $\left(\Delta_{\text {int }} H^{\circ}\right)$ of Erythritol and L-Threitol at $298.15 \mathrm{~K}^{a}$

\begin{tabular}{cccccc}
\hline compound & $\begin{array}{c}\Delta_{\text {sub }} H^{\circ} / \\
\mathrm{kJ} \mathrm{mol}^{-1}\end{array}$ & $\begin{array}{c}H_{\text {conf }}^{\mathrm{g}} \\
\mathrm{kJ} \mathrm{mol}^{-1}\end{array}$ & $\begin{array}{c}H_{\text {conf }}^{\mathrm{c}} \\
\mathrm{kJ} \mathrm{mol}^{-1}\end{array}$ & $\begin{array}{c}\Delta_{\text {conf }} H^{\circ} / \\
\mathrm{kJ} \mathrm{mol}^{-1}\end{array}$ & $\begin{array}{c}\Delta_{\text {int }} H^{\circ} / \\
\mathrm{kJ} \mathrm{mol}^{-1}\end{array}$ \\
\hline erythritol & 140 & -1205921 & -1205900 & -21 & -161 \\
L-threitol & 123 & -1205931 & -1205897 & -34 & -157
\end{tabular}

${ }^{a}$ Enthalpy of the molecules with crystal geometry $\left(H_{\text {conf }}^{\mathrm{c}}\right)$ and in the gas state $\left(H_{\text {conf }}^{\mathrm{g}}\right)$.

3.2. Determination of the Conformational Change Enthalpy by DFT Calculations. To determine $\Delta_{\text {int }} H^{\circ}$ from $\Delta_{\text {sub }} H^{\circ}$ using eq 1 , we need the value corresponding to $\Delta_{\text {conf }} H^{\circ}$. This quantity can be obtained by the difference between the enthalpy of the molecule in the gas state $\left(H_{\text {conf }}^{\mathrm{g}}\right)$ and the enthalpy of the free molecule retaining the molecular conformation exhibited in the crystal $\left(H_{\text {conf }}^{\mathrm{c}}\right)$.

$$
\Delta_{\text {conf }} H^{\circ}=H_{\text {conf }}^{\mathrm{g}}-H_{\text {conf }}^{\mathrm{c}}
$$

In recent work performed in our research group, density functional theory calculations using the B3LYP functional and the $6-311++\mathrm{G}(\mathrm{d}, \mathrm{p})$ basis set were carried out on the isolated molecules of erythritol and L-threitol. ${ }^{17}$ Full geometry optimizations with vibrational frequency calculations allowed the determination of the total energy, enthalpy, and Gibbs energy at 298.15 K for the most stable conformers. Thirty-five conformers were considered for the meso isomer and eighteen for threitol. The molecular structures of three of the most relevant conformers for each diastereomer are displayed in Figures 1 and 2. These conformers are representative of the lowest-energy conformers and of the diversity of hydrogen bonds observed in the monomeric form. As can be seen, a different carbon chain is shown by both isomers. While erythritol conformers exhibit preferentially a gauche clockwise or anticlockwise conformation relative to the CCCC backbone torsion, a trans configuration is observed for threitol. These structural features give rise to different numbers and strengths of intramolecular interactions, and therefore, a significant difference between the enthalpies of both isomers is expected.

The enthalpy of the molecules in the gas state was taken as the weighed mean value obtained from the enthalpies and Boltzmann populations of the conformers (see ref 17 for details), according to the following expression:

$$
H_{\mathrm{conf}}^{\mathrm{g}}=\sum_{i} H(i) P(i)
$$

where $H(i)$ and $P(i)$ are the enthalpy and equilibrium population
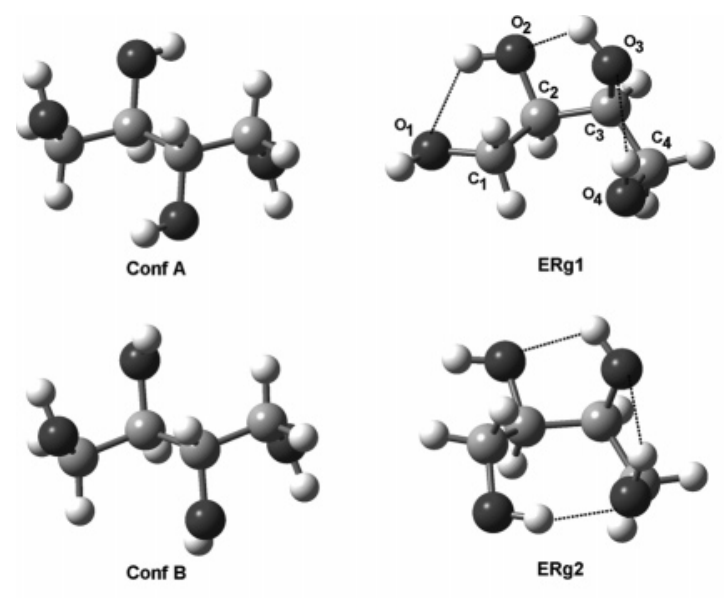

(a)
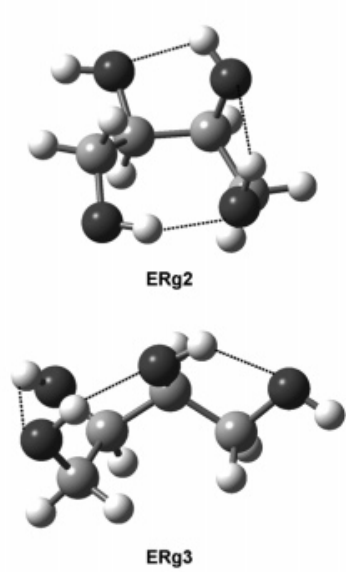

(b)

Figure 1. Crystal conformations (a) and three relevant conformers of erythritol in the gas phase (b). The crystal molecular conformations were taken from the fractional atomic coordinates given in ref 18 . Conf A and conf B refer to the two possible conformations adopted by erythritol in the crystal lattice, which differ from one another only by the positions of the two hydrogen atoms of the hydroxyls bonded to the middle carbon atoms. Intramolecular hydrogen bonds are shown by dashed lines. Atom numbering is presented in ERg1.

of each conformer, respectively. The values of $H_{\text {conf }}^{\mathrm{g}}$ obtained for the two molecules are presented in Table 3.

The neutron ${ }^{18}$ and $\mathrm{X}$-ray ${ }^{19}$ diffraction data available in the literature for erythritol and L-threitol, respectively, were used to obtain the crystal conformations for the two molecules, which are displayed in Figures 1 and 2. The $\mathrm{O}-\mathrm{H}$ and $\mathrm{C}-\mathrm{H}$ bond lengths given by $\mathrm{X}$-ray diffraction technique are on average $0.1-$ $0.2 \AA$ shorter than the internuclear distances. ${ }^{20}$ Therefore, singlepoint calculations cannot be used to determine the energy of the L-threitol isolated molecule taken directly from the X-ray data, as this results in an excessively large conformational change enthalpy, thus without physical chemical meaning. Hence, for obtaining the energy of the isolated L-threitol molecule retaining the crystal geometry, a partial optimization was carried out in which the $\mathrm{O}-\mathrm{H}$ and $\mathrm{C}-\mathrm{H}$ distances were relaxed, while all the other parameters were constrained to remain fixed. Regarding erythritol, as the crystal structure was determined by neutron diffraction, the $\mathrm{C}-\mathrm{H}$ and $\mathrm{O}-\mathrm{H}$ distances are accurately determined. Thus, the determination of the crystal 


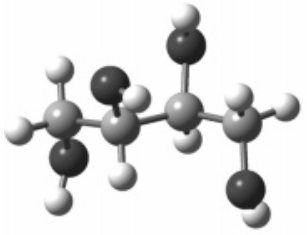

(a)
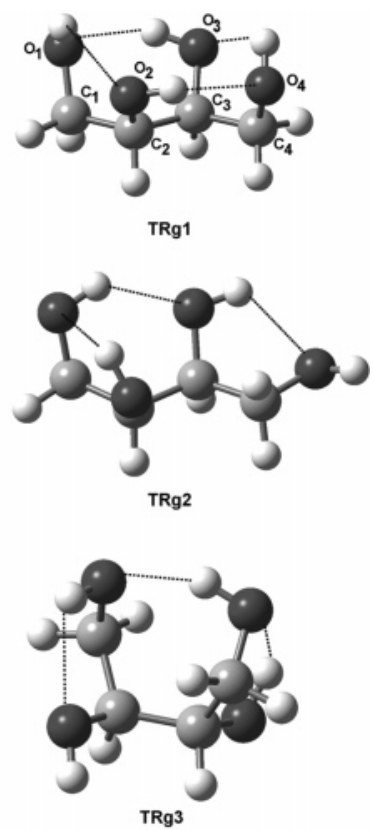

(b)
Figure 2. Crystal conformation (a) and three relevant conformers of L-threitol in the gas phase (b). The crystal molecular conformation was taken from the fractional coordinates given in ref 19. Intramolecular hydrogen bonds are shown by dashed lines. Atom numbering is presented in $\operatorname{TRg} 1$.

conformation energy using either single-point or partial optimization yielded similar energy values.

The calculations were performed with the Gaussian 98 program package ${ }^{21}$ using the same approximation method and basis set as described above for the gas-state calculations. The values of $H_{\text {conf }}^{\mathrm{c}}$ for erythritol and L-threitol are given in Table 3.

According to the neutron diffraction data, ${ }^{18}$ the erythritol molecule at $22.6 \mathrm{~K}$ can adopt two different conformations in the crystal with occupancies of $85 \%$ (conformation A) and $15 \%$ (conformation B). From the molecular structure, one can see that the only difference between conformations $\mathrm{A}$ and $\mathrm{B}$ lies in the relative position of $\mathrm{H}\left(\mathrm{O}_{2}\right)$ and $\mathrm{H}\left(\mathrm{O}_{3}\right)$ atoms (see Figure 1). Assuming the Boltzmann distribution, the contributions of the two conformations to the structure of erythritol at $298.15 \mathrm{~K}$ are $53 \%$ of $\mathrm{A}$ and $47 \%$ of B. Hence, the value ascribed to $H_{\text {conf }}^{\mathrm{c}}$ was calculated by the following expression

$$
H_{\mathrm{conf}}^{\mathrm{c}}=0.53 H_{\mathrm{confA}}^{\mathrm{c}}+0.47 H_{\mathrm{confB}}^{\mathrm{c}}
$$

\section{Discussion}

The values obtained for the enthalpy corresponding to the steps considered in the sublimation process and quoted in Table 3 clearly point out the role played by the molecular conformation. The contribution given by $\Delta_{\text {conf }} H^{\circ}$ is high enough not to be ignored in the interpretation of the intermolecular forces in the solid.

In the solid state, a distended carbon chain is observed for both isomers. This structure and the $\mathrm{OH}$ group orientations favor the intermolecular interaction but not internal bonds. The enthalpy released in the formation of the intramolecular bonds contributes significantly to the conformational enthalpy change as the molecules pass from the solid to the gas. It is surprising to see that the difference in $\Delta_{\text {conf }} H^{\circ}$ between erythritol and threitol is mainly due to the difference of the conformations in the gas state.

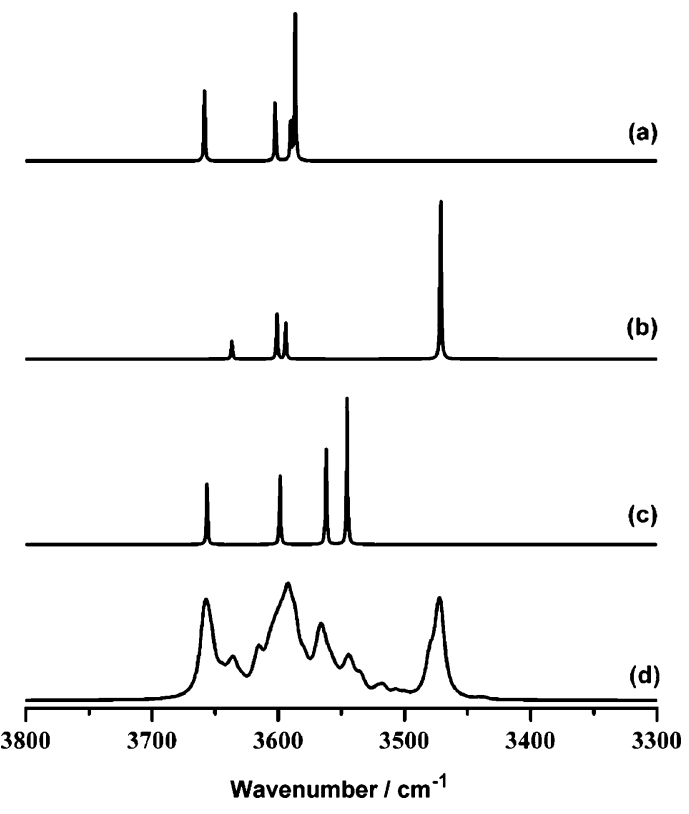

Figure 3. Calculated (B3LYP/6-311++ $\left.\mathrm{G}^{* *}\right)$ vibrational spectra of ERg1 (a), ERg2 (b), ERg3 (c), and the conformational mixture of erythritol in the gas state at $298.15 \mathrm{~K}$ (d).

The thermodynamic property directly related with the intermolecular forces in the solid state is $\Delta_{\text {int }} H^{\circ}$, whose absolute value can be significantly different from that of $\Delta_{\text {sub }} H^{\circ}$. This happens with erythritol and threitol. For any of the isomers, the absolute value of $\Delta_{\text {int }} H^{\circ}$ is much higher than that of $\Delta_{\text {sub }} H^{\circ}$. Moreover, the information on the comparison of the intermolecular interactions in the solid phase between the compounds under study given by $\Delta_{\text {int }} H^{\circ}$ and $\Delta_{\text {sub }} H^{\circ}$ is different. While the difference between $\Delta_{\text {sub }} H^{\circ}$ is $17 \mathrm{~kJ} \mathrm{~mol}^{-1}$, that observed for $\Delta_{\text {int }} H^{\circ}$ is only $4 \mathrm{~kJ} \mathrm{~mol}^{-1}$.

Another conclusion drawn from the data presented in this paper and deserving attention is concerned with the gas phase taken as the reference state. Indeed, this state is commonly considered a reference state in thermodynamic processes and understood at a low pressure as free from intermolecular forces. Hence, the value obtained for the thermodynamic function is usually ascribed to the interaction in the condensed state of the matter involved. The data of Table 3 prove how such an interpretation can be far from correct. For erythritol and threitol, the structural difference between $H_{\text {conf }}^{\mathrm{g}}$ in the gas state is much larger than that observed in the solid state.

Vibrational spectroscopy can give a valuable contribution to understanding the energy differences between erythritol and threitol in the gas phase. In fact, on one hand, intramolecular hydrogen bonds are the most important features of the structure of the isolated molecules and, therefore, the main contribution to the energy. On the other hand, infrared spectroscopy is one of the most appropriate methods to study this kind of interaction.

In Figure 3, the calculated vibrational spectra in the $\mathrm{O}-\mathrm{H}$ stretching region of the three conformers of erythritol shown in Figure 1 are presented. The spectra were obtained at the B3LYP/6-311++ $\mathrm{G}^{* *}$ level of theory. This figure also includes the calculated spectrum of the conformational mixture in the gas state at $298.15 \mathrm{~K}$, which was obtained by adding the population-weighed theoretical spectra of all conformers (see ref 17 for details). Under the same criteria, similar pictures are given for threitol in Figure 4.

The assignment of the frequencies for the conformers referred to above was performed by Gaussview animation of the vibrational modes and is given in Table 4. The vibrational 

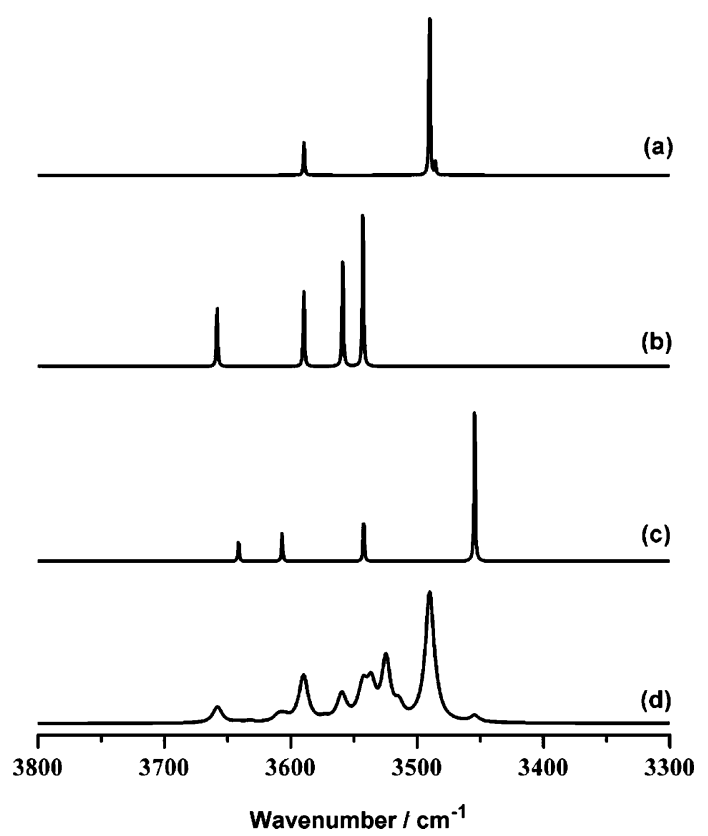

Figure 4. Calculated vibrational spectra of TRg1 (a), TRg2 (b), TRg3 (c), and the conformational mixture of L-threitol in the gas state at $298.15 \mathrm{~K}(\mathrm{~d})$.

TABLE 4: Frequencies (v), Intensities (int), and Assignments of the IR-Calculated OH-Stretching Vibrations (B3LYP/6-311++G**) for Three of the Most Relevant Conformers of Erythritol and L-Threitol

\begin{tabular}{|c|c|c|c|c|c|}
\hline$v / \mathrm{cm}^{-1}$ & $\operatorname{int}^{a}$ & assignment $^{b}$ & $v / \mathrm{cm}^{-1}$ & $\operatorname{int}^{a}$ & assignment $^{b}$ \\
\hline \multicolumn{3}{|r|}{ ERg1 } & \multicolumn{3}{|r|}{ TRg1 } \\
\hline 3659 & 41 & $v \mathrm{O}_{1} \mathrm{H}_{\text {free }}$ & 3590 & 67 & $\left(v \mathrm{O}_{1} \mathrm{H}+v \mathrm{O}_{4} \mathrm{H}\right)$ ip \\
\hline 3602 & 43 & $\nu \mathrm{O}_{4} \mathrm{H}$ & 3589 & 31 & $\left(v \mathrm{O}_{1} \mathrm{H}+v \mathrm{O}_{4} \mathrm{H}\right) \mathrm{op}$ \\
\hline 3590 & 33 & $\left(v \mathrm{O}_{2} \mathrm{H}+\nu \mathrm{O}_{3} \mathrm{H}\right)$ op & 3490 & 462 & $\left(v \mathrm{O}_{2} \mathrm{H}+\nu \mathrm{O}_{3} \mathrm{H}\right)$ op \\
\hline 3587 & 119 & $\left(v \mathrm{O}_{2} \mathrm{H}+v \mathrm{O}_{3} \mathrm{H}\right)$ ip & 3485 & 35 & $\left(v \mathrm{O}_{2} \mathrm{H}+v \mathrm{O}_{3} \mathrm{H}\right)$ ip \\
\hline \multicolumn{3}{|r|}{ ERg2 } & \multicolumn{3}{|r|}{ TRg2 } \\
\hline 3637 & 32 & $\nu \mathrm{O}_{2} \mathrm{H}_{\text {free }}$ & 3658 & 52 & $\nu \mathrm{O}_{4} \mathrm{H}_{\text {free }}$ \\
\hline 3601 & 67 & $\nu \mathrm{O}_{3} \mathrm{H}$ & 3590 & 62 & $\nu \mathrm{O}_{3} \mathrm{H}$ \\
\hline 3594 & 55 & $\nu \mathrm{O}_{4} \mathrm{H}$ & 3559 & 97 & $v \mathrm{O}_{2} \mathrm{H}$ \\
\hline 3471 & 278 & $v \mathrm{O}_{1} \mathrm{H}$ & 3543 & 126 & $\nu \mathrm{O}_{1} \mathrm{H}$ \\
\hline \multicolumn{3}{|r|}{ ERg3 } & \multicolumn{3}{|r|}{ TRg3 } \\
\hline 3656 & 52 & $v \mathrm{O}_{4} \mathrm{H}_{\text {free }}$ & 3641 & 39 & $\nu \mathrm{O}_{2} \mathrm{H}_{\text {free }}$ \\
\hline 3599 & 62 & $v \mathrm{O}_{3} \mathrm{H}$ & 3607 & 50 & $v \mathrm{O}_{1} \mathrm{H}$ \\
\hline 3562 & 86 & $\nu \mathrm{O}_{2} \mathrm{H}$ & 3542 & 80 & $\nu \mathrm{O}_{3} \mathrm{H}$ \\
\hline 3545 & 125 & $v \mathrm{O}_{1} \mathrm{H}$ & 3454 & 271 & $v \mathrm{O}_{4} \mathrm{H}$ \\
\hline
\end{tabular}

${ }^{a}$ Calculated intensities in $\mathrm{Km} \mathrm{mol}^{-1} \cdot{ }^{b} v$, stretching; as, asymmetric; s, symmetric; op, out-of-phase vibration; in, in-phase vibration.

frequencies have been scaled with 0.948 . This value was determined on the basis of the comparison of the $\mathrm{OH}$-stretching frequencies of butanodiol isomers in $\mathrm{CCl}_{4}$ solution with those calculated for the monomeric forms of these molecules at the B3LYP/6-311++G** level of theory. ${ }^{22}$

The structures of erythritol and threitol in the gas state are stabilized by several types of hydrogen bonds: between vicinal groups (general denomination 1-2), second neighbors (1-3), and the two terminal groups (1-4). In the meso form, the shift of $v_{\max }$ corresponding to the stretching vibration of the hydrogenbonded hydroxyls to lower wavenumbers is on the average 60, 80 , and $170 \mathrm{~cm}^{-1}$ for $1-2,1-3$, and 1-4 bonds, respectively. In threitol, the shifts are 70,130, and $200 \mathrm{~cm}^{-1}$. As the displacement of the stretching band of a group under the influence of a hydrogen bond is related with the strength of the interaction, the following conclusions can be made: First, the types of hydrogen bonds considered above have distinct strengths and are ordered in both isomers as 1-2 $<1-3<1-4$. Second, the
TABLE 5: Population of Erythritol and L-Threitol Conformers with Different Types of Intramolecular Hydrogen Bonds

\begin{tabular}{lcc}
\hline & \multicolumn{2}{c}{ conformer population/\% } \\
\cline { 2 - 3 } OH group & erythritol & L-threitol \\
\hline free & 100 & 42 \\
intramolecular & & \\
$1-2$ & 99 & 100 \\
$1-3$ & 24 & 84 \\
$1-4$ & 19 & 3
\end{tabular}

hydrogen bonds of a certain type are stronger in threitol than in erythritol. Besides the difference in the energy of the hydrogen bonds between erythritol and threitol, the number of conformers included in each type of bond varies from one isomer to the other. The populations of erythritol and L-threitol conformers with different types of hydrogen bonds are presented in Table 5. These values were obtained from the Boltzmann populations of the most stable conformers given in ref 17. Most of the conformers of both isomers exhibit hydrogen bonds between vicinal groups, but in erythritol, all conformers have one or two free hydroxyl groups, and in threitol, only a very few hydroxyls are free. On the contrary, threitol is richer in more energetic 1-3 hydroxyl bonds than erythritol.

The features in hydrogen boding just referred to are manifested in the spectra of the conformational mixture of the gas state. In fact, the bands located at lower wavenumbers in threitol are more intense than those at higher wavenumbers. In erythritol, the intensities of the peaks are more uniformly distributed.

The $\mathrm{OH}$ stretching vibration spectra are in agreement with the difference of enthalpy calculated for the isomers.

\section{Concluding Remarks}

The first conclusion deserving attention is concerned with the need to know the value of a thermodynamic property in the gas state when thermodynamics is used in processes involving this state. As no intermolecular forces are commonly taken into account in the gas phase at low pressure, the difference of a thermodynamic quantity, say, enthalpy of sublimation, between the compounds under study is often ascribed to the differences between molecular interactions in the condensed state of matter. Although accounting for the difference in the thermodynamic function in the gas state is always needed, it assumes a particular importance in polyfunctional compounds capable of establishing internal hydrogen bonds. For erythritol and threitol, the differences in enthalpy of molecular conformations in the gas state are higher than between the enthalpy of interaction in the solid state.

The results presented in this work prove the advantage in decomposing a thermodynamic property into terms with structural meaning, which can be determined by an independent method. The recent progress attained by computational methods turns them into valuable complements for understanding thermodynamic properties. Indeed, from the values obtained experimentally for the enthalpy of sublimation and from those calculated for the enthalpy of the molecular conformation in the gas and solid states, quantitative information on the molecular structure in both phases is obtained.

The spectra calculated for erythritol and threitol allow the interpretation of the difference in the enthalpy in the gas phase between these isomers.

Acknowledgment. A. J. Lopes Jesus and Luciana I. N. Tomé acknowledge Fundação para a Ciência e a Tecnologia (FCT), Lisbon, for financial support: grants SFRH/BD/9110/2002 and SFRH/BD/12373/2003, respectively. 


\section{References and Notes}

(1) de Cock, P.; Bechert, C. L. Pure Appl. Chem. 2002, 74, 1281.

(2) Endo, K.; Amikawa, S.; Matsumoto, A.; Sahashi, N.; Onoue, S. Int. J. Pharm. 2005, 290, 63.

(3) Wang, W.; Vas, G.; Dommisse, R.; Loones, K.; Claeys, M. Rapid Commun. Mass Spectrom. 2004, 18, 1787.

(4) Pierce, A. E. Silylation of organic compounds; Pierce Chemical Company: Rockford, MD, 1968.

(5) Sabbah, R.; An, X. W.; Chickos, J. S.; Leitão, M. L. P.; Roux, M.

V.; Torres, L. A. Thermochim. Acta 1999, 331, 93.

(6) Eusébio, M. E.; Jesus, A. J. L.; Cruz, M. S. C.; Leitão, M. L. P.; Redinha, J. S. J. Chem. Thermodyn. 2003, 35, 123.

(7) Ruzicka, K.; Majer, V. J. Phys. Chem. Ref. Data 1994, 23, 1.

(8) Barone, G.; Della Gatta, G.; Ferro, D.; Piacente, V. J. Chem. Soc., Faraday Trans. 1990, 86, 75

(9) Reid, R. C.; Prausnitz, J. M.; Polling, B. E. The properties of gases and liquids; McGraw-Hill: New York, 1987.

(10) Flynn, J. H. Thermochim. Acta 1974, 8, 69.

(11) Flynn, J. H. Thermochim. Acta 1993, 217, 129.

(12) Mraw, S. C.; Naas, D. F. J. Chem. Thermodyn. 1979, 11, 567.

(13) Reshetni, Ma. Russ. J. Phys. Chem. 1969, 43, 1254.

(14) Arvidsson, K.; Falk, B.; Sunner, S. Chem. Scr. 1976, 10, 193.

(15) Ferloni, P.; Della Gatta, G. Thermochim. Acta 1995, 266, 203.

(16) Afeefy, H. Y.; Liebman, J. F.; Stein, S. E. Neutral Thermochemical Data. In NIST Chemistry WebBook, NIST Standard Reference Database
Number 69; Linstrom, P. J., Mallard, W. G., Eds.; National Institute of Standards and Technology: Gaithersburg, MD, 20899; accessed June 2005 (http://webbook.nist.gov)

(17) Jesus, A. J. L.; Tomé, L. I. N.; Rosado, M. T. S.; Leitão, M. L. P.; Redinha, J. S. Carbohydr. Res. 2005, 340, 283.

(18) Ceccarelli, C.; Jeffrey, G. A.; McMullan, R. K. Acta Crystallogr., Sect. B 1980, 36, 3079.

(19) Kopf, J.; Morf, M.; Zimmer, B.; Haupt, E. T. K.; Jarchow, O.; Koll, P. Carbohydr. Res. 1993, 247, 119.

(20) Desiraju, G. R.; Steiner, T. The Weak Hydrogen Bond; Oxford University Press, Inc.: New York, 1999.

(21) Frisch, M. J.; Trucks, G. W.; Schlegel, H. B.; Scuseria, G. E.; Robb, M. A.; Cheeseman, J. R.; Zakrzewski, V. G.; Montgomery, J. A., Jr.; Stratmann, R. E.; Burant, J. C.; Dapprich, S.; Millam, J. M.; Daniels, A. D.; Kudin, K. N.; Strain, M. C.; Farkas, O.; Tomasi, J.; Barone, V.; Cossi, M.; Cammi, R.; Mennucci, B.; Pomelli, C.; Adamo, C.; Clifford, S.; Ochterski, J.; Petersson, G. A.; Ayala, P. Y.; Cui, Q.; Morokuma, K.; Malick, D. K.; Rabuck, A. D.; Raghavachari, K.; Foresman, J. B.; Cioslowski, J.; Ortiz, J. V.; Stefanov, B. B.; Liu, G.; Liashenko, A.; Piskorz, P.; Komaromi, I.; Gomperts, R.; Martin, R. L.; Fox, D. J.; Keith, T.; Al-Laham, M. A.; Peng, C. Y.; Nanayakkara, A.; Gonzalez, C.; Challacombe, M.; Gill, P. M. W.; Johnson, B. G.; Chen, W.; Wong, M. W.; Andres, J. L.; Head-Gordon, M.; Replogle, E. S.; Pople, J. A. Gaussian 98, revision A.9; Gaussian, Inc.: Pittsburgh, PA, 1998.

(22) Jesus, A. J. L.; Rosado, M. T. S.; Leitão, M. L. P.; Redinha, J. S. J. Phys. Chem. A 2003, 107, 3891 